\title{
Food consumption patterns and nutrition transition in South-East Asia
}

\author{
Nur Indrawaty Lipoeto ${ }^{1, *}$, Khor Geok $\operatorname{Lin}^{2}$ and Imelda Angeles-Agdeppa ${ }^{3}$ \\ 'Department of Nutrition, Faculty of Medicine, Andalas University, Jl Perintis Kemerdekaan, Padang - 25127, \\ Indonesia: ${ }^{2}$ School of Pharmacy and Health Sciences, Department of Nutrition and Dietetics, Faculty of Medicine \\ \& Health, International Medical University, Bukit Jalil, Kuala Lumpur, Malaysia: ${ }^{3}$ Department of Science and \\ Technology of the Republic of the Philippines, Food and Nutrition Research Institute (FNRI), Taguig City, \\ Metro Manila, Philippines
}

Submitted 9 January 2012: Final revision received 2 June 2012: Accepted 3 September 2012: First published online 19 November 2012

\begin{abstract}
Objective: The present study was done to confirm the relationship between changes in food patterns and nutrition transition in three South-East Asian countries, namely the Philippines, Malaysia and Indonesia.

Design: This was a cross-sectional study conducted between August 2008 and August 2009 using three methods: interviews, focus group discussions and analyses of government reports.

Setting: The study was conducted in rural and urban areas in Manila and Calabanga (Philippines), Selangor and Kuala Selangor (Malaysia), and Padang, Pariaman Tanah Datar and Limapuluh Kota (West Sumatra, Indonesia).

Subjects: Adults aged 18 to 77 years.

Results: The results showed that Filipinos, Malaysians and Indonesians have retained many aspects of their traditional diets. In fact, most participants in the study considered Western-style and franchise fast foods as snack or recreational foods to be consumed once in a while only. However, a significant difference was noted between urban and rural areas in food varieties consumed. Participants in urban areas consumed more varieties of traditional foods owing to their availability and the participants' food purchasing power. Although traditional food patterns were maintained by most of the participants, more sugar and vegetable oils were consumed and added to the traditional recipes.

Conclusions: The rapid nutrition transition in this region may be due, instead, to increasing food availability and food purchasing power, rather than to a shift in food preferences towards modern Western foods.
\end{abstract}

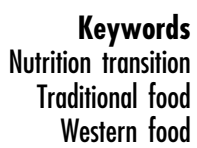

Many developing countries are experiencing a rapid nutrition transition characterized by the double burden of disease, whereby chronic diseases become more prevalent while infectious diseases remain undefeated. This is a universal trend dominating the health profile of increasingly large numbers of people in developing countries. The epidemiological transition and the concurrent shift in diet, physical activity and body composition in many developing countries have been rapid, unlike the gradual transition in the USA and most European countries ${ }^{(1)}$. Reports from Asian countries such as Korea, India and Japan, and from countries in South America, indicate that the rapid change in dietary habits and body composition occurred after their countries achieved dietary sufficiency at the national level ${ }^{(2-4)}$. In India, the rapid socio-economic transition resulted in rapid changes in dietary patterns ${ }^{(5)}$.

Globalization has been cited as one reason for the rapid nutrition transition in developing countries. Globalization increases accessibility to Western supermarket and fastfood franchises ('McDonaldization'). Cheap vegetable fat and sugar have flooded the market in developing countries, thereby increasing the consumption of sweet soda pops, biscuits and snacks produced by multinational companies. Current diets in many developing countries have increasing proportions of energy derived from fat (primarily vegetable oils) and also from refined carbohydrates $^{(6)}$. An association was found between the increase in Western-style, fat-rich foods (such as butter and margarine, cheese, bread, ham and sausage) and higher mortality rates from degenerative diseases such as heart disease and cancer $^{(7)}$.

The present study was conducted to confirm whether changing food patterns correspond to nutrition transition in the South-East Asian region. The study also aimed to answer how far the people in three countries, namely the Philippines, Malaysia and Indonesia, have moved 
away from their traditional foods towards the modern style of food consumption.

\section{Methods}

The study was conducted in the Philippines, Malaysia and Indonesia between August 2008 and August 2009. In each country, one rural area and one urban area were selected. It was presumed that the rural area still maintains the traditional food pattern, while the urban area has changed considerably. In the Philippines, Manila was chosen as the urban area, while Calabanga in the province of Camarines Sur was chosen as the rural area. In Malaysia, the study was done only among the Malay population. Bandar Baru Bangi - Selangor was chosen as the urban area and Tanjong Karang - Kuala Selangor was the rural area selected. In Indonesia, the study was done in West Sumatra. Padang was chosen as the urban area and three villages from three different districts were chosen as the rural areas.

Three methods were used in the study. The first was the focus group discussion (FGD), which was used to obtain an in-depth understanding of the people's food culture. Discussions were conducted to get information on food habits, food preparation and changes. Invitations to participate in the FGD were disseminated through the village mayor, and also through doctors and midwives. The invitations were disseminated to two groups of people: the young generation (below 30 years of age) and older generation (above 50 years of age). All adults who originally lived in the selected places and responded to the invitations were selected as participants in the FGD. Each session was tape-recorded and lasted up to $1.5 \mathrm{~h}$.

Interview was the second method; it was used to determine health status, lifestyles and food consumption patterns and to differentiate between people in rural areas and in urban areas in terms of health status, lifestyles and food consumption patterns. This method was intended to document the different kinds of traditional foods and the difference between rural and urban participants in terms of food variations. Respondents were selected by systematic random selection through the list of adults in the places.

The third method involved analysing government reports and national surveys on socio-economic changes. These reports were used to determine the extent of nutrition transition in the countries.

All data gathered using the three methods were analysed qualitatively and quantitatively to determine the relationship between traditional food consumption and nutrition transition in Malaysia, the Philippines and Indonesia. The project was approved by the Ethics Committee of the Faculty of Medicine and Health Sciences of University Putra Malaysia (UPM/FPSK/PADS/T7-MJKEtikaPer/F01) and the Ethics Committee of the Faculty of Medicine of Andalas University.

\section{Results}

\section{Characteristics of the respondents}

The FGD were the major source of information for the present study. In the Philippines, one FGD each was done in the urban and rural areas. The discussions were conducted among ten to twelve participants aged 18-60 years. In Malaysia, three FGD were done. In the urban area, two FGD were conducted in Bandar Baru Bangi among females only, and then among male participants only. In the rural area, the FGD was done in Tanjong Karang among male participants aged 35-64 years. In Indonesia, the FGD were conducted in Padang, the capital city of West Sumatra, where Kalumbuk was situated. The second village was Nareh, situated in the coastal region south of the Padang Pariaman municipalities, about $45 \mathrm{~km}$ from Padang. The other two villages, Pincuran Panjang and Kubang, lay in the mountainous region in the municipalities of Tanah Datar and Limapuluh Kota, respectively. These two villages are in the heartland of West Sumatra. Pincuran Panjang is about $60 \mathrm{~km}$ from Padang, while Kubang is about $110 \mathrm{~km}$ from Padang. Invitations to participate in the FGD were disseminated through the village mayor, and also through doctors and midwives. These invitations were intended for the adult women in the villages. Thirteen women, aged 46-67 years, participated in the FGD in Nareh. In Kalumbuk, nine women aged 30-67 years joined in the FGD; while in Pincuran Panjang, participants were seven women aged 46-81 years. In Kubang, thirteen women aged 33-77 years joined the FGD. Some other complementary methods were used to obtain data about the food culture, including informal interviews and observations.

Meanwhile, the major source of information to determine food patterns was the interview. Ninety individuals in the Philippines, ninety-five in Malaysia and 189 individuals in Indonesia were interviewed. On the average, the participants in the urban areas were younger and had higher education levels (87\%, 72\% and 62\% in the Philippines, Malaysia and Indonesia, respectively) compared with those in the rural areas. The interviews were done mostly with women. Government reports provided data on food consumption patterns.

\section{Food patterns}

Most of the participants in the Philippines used coconut oil as their source of fat: only $22 \%$ in the urban areas and $7 \%$ in the rural areas did not use coconut oil. However, butter was used even more widely. In the urban areas, $40 \%$ used butter as their source of fat, while in the rural areas, $47 \%$ did the same. In Malaysia, none of the participants used coconut oil or butter; all used palm oil as their source of fat. In Indonesia, coconut oil had been gradually replaced by palm oil due to the increasing price of coconut oil.

Food variation scores were assigned according to the weekly consumption frequency of fifty traditional foods 
resulting from the FGD. Savige et al. have used food variety to determine a food variety score representing the total number of foods consumed from specific food groups in a given time period ${ }^{(8)}$. Table 1 shows that participants in the urban areas had significantly higher scores in terms of food variation compared with participants in the rural areas $(P=0 \cdot 02)$. Twenty-six per cent of participants in the urban areas compared with only $9 \%$ in the rural areas regularly consumed snacks after dinner. Filipino respondents reported that they consumed food more frequently now than before.

Breakfast food patterns in the Philippines showed no difference in food preference between the urban and the rural participants. Although bread, crackers or oats have been chosen as alternative foods for breakfast, rice - be it boiled or fried - remained the main food staple both for the rural and the urban participants (Table 2).

In Malaysia, the results showed that nasi lemak was the first choice in terms of breakfast food for most of the participants, both from the urban and rural areas. Compared with participants from rural areas who had limited food choices for breakfast, participants from urban areas had more local breakfast food favourites such as roti canai, chapatti and bread. Breakfast was usually

Table 1 Food variation scores*

\begin{tabular}{lrrr}
\hline & Mean & SD & Range \\
\hline Urban & 112.92 & 63.09 & $30-332$ \\
Rural & 55.96 & 25.46 & $7-114$ \\
\hline
\end{tabular}

*Significance difference at $P=0.02$. served with tea or teb tarik, which literally means 'pulled tea' (Table 3).

In Indonesia, food was usually prepared mid-morning, and consumed as lunch and dinner that day and as breakfast the following morning. Hot food eaten as breakfast was usually dinner left over from the previous evening. Breakfast could be either sweet food or hot food that contained chillies.

The food patterns for lunch and dinner in urban and rural areas in the Philippines consisted of rice, vegetables and fish. These were prepared in traditional ways such as sinigang and kaldereta. Sinigang is stewed fish/meat soured by tamarind, while kaldereta is stewed pork with tomato sauce (Table 4).

The lunch and dinner food patterns in Malaysia consisted of rice and vegetables, plus either chicken or fish. Boiled rice was served with sautéed vegetables, while the chicken or fish was deep fried or boiled in coconut milk. Chicken curry and mutton curry were popular dishes in Malaysia (Table 5).

In Indonesia, basic daily dishes consisted of steamed rice, a hot fried dish and a coconut milk dish, with minimal variation from breakfast to evening meals. Lunch was considered to be the most important meal of the day. The core component of lunch and dinner was usually rice. Other carbohydrate-rich foods included cassava, corn, sago or noodles, although they were sometimes considered as snacks. The protein source consumed daily was fish. In the present study, participants in the three of the four villages reported consuming fish four to six times weekly. Beef and chicken were mainly prepared for special occasions.

Table 2 Meal components and preparation methods: determinants of breakfast pattern in the Philippines

\begin{tabular}{llllll}
\hline & & Meal components & & \\
\cline { 2 - 3 } & Core items & Secondary items & & Preparation methods & Meal pattern \\
\hline \multirow{2}{*}{ Urban } & Rice, bread & Quaker oats, crackers, champorado* & & Fried rice \\
& Fish, egg & Hotdog, meatloaf & Fried & Scrambled egg \\
& Coffee & Chocolate drink & Noodles & Fried, scrambled & Coffee \\
& Rice, bread & Hotdog & Fried & Fried rice \\
& Egg, fish & Instant coffee & & Fried & Fried fish \\
& & & & Instant coffee \\
\hline
\end{tabular}

${ }^{*}$ Champarado $=$ glutinous rice and coconut milk.

Table 3 Meal components and preparation methods: determinants of breakfast pattern in Malaysia

\begin{tabular}{|c|c|c|c|c|}
\hline & \multicolumn{2}{|c|}{ Meal components } & \multirow[b]{2}{*}{ Preparation methods } & \multirow[b]{2}{*}{ Meal pattern } \\
\hline & Core items & Secondary items & & \\
\hline Urban & $\begin{array}{l}\text { Nasi lemak*/roti canai }{ }^{*} / \text { bread } \\
\text { Egg } \\
\text { Teh tarik } k^{*} \text {, coffee }\end{array}$ & $\begin{array}{l}\text { Noodles, high-fibre bread, cereal } \\
\text { Burger } \\
\text { Chocolate milk }\end{array}$ & Fried & $\begin{array}{l}\text { Nasi lemak } \\
\text { Salted egg } \\
\text { Teh tarik }\end{array}$ \\
\hline Rural & $\begin{array}{l}\text { Rice/nasi lemak } \\
\text { Egg, fish } \\
\text { Teh tarik }\end{array}$ & Banana & Boiled/fried & $\begin{array}{l}\text { Fried banana } \\
\text { Teh tarik }\end{array}$ \\
\hline
\end{tabular}

${ }^{*}$ Nasi lemak = rice cooked with coconut milk; roti canai $=$ flat bread; teh tarik= 'pulled tea'. 
Table 4 Meal components and preparation methods: determinants of lunch and dinner pattern in the Philippines

\begin{tabular}{llllll}
\hline \multicolumn{2}{c}{ Meal components } & & \\
\cline { 2 - 3 } & Core items & Secondary items & Preparation methods & Meal pattern \\
\hline \multirow{2}{*}{ Urban } & Rice & Noodle & Sinigang* $^{*}$ & Pattern 1: \\
& Vegetable & Sweet potato & Kaldereta $^{*}$ & Rice \\
& Fish/pork/chicken & Sardines & Vegetables with coconut milk, sautéed with maggi & Sinigang (meat, vegetables, sour soup) \\
Rural & Rice & Noodles & Sinigang & Pattern 2: \\
& Vegetable & & Kaldereta & Rice \\
& Fish/pork/chicken & & Vegetables with coconut milk, sautéed with magi & Fried fish \\
& & & Ginataan vegetables \\
\hline
\end{tabular}

Sinigang = stewed fish/meat soured by tamarind; kaldereta = stewed pork with tomato sauce.

Table 5 Meal components and preparation methods: determinants of lunch and dinner pattern in Malaysia

\begin{tabular}{llllll}
\hline & \multicolumn{2}{c}{ Meal components } & & \\
\cline { 2 - 3 } & Core items & Secondary items & & Preparation methods & Meal pattern \\
\hline Urban & Rice & Noodles & Boiled & Pattern 1: \\
& Vegetables & & Sautéed & Rice \\
& Chicken, meat, fish & & Sautéed vegetables \\
Rural & Rice & Noodles & & Boiled & Meat and coconut milk \\
& Vegetables & & Sautéed & Pattern 2: \\
& Fish & & Fried, coconut milk & Raw vegetables \\
& & & & Fried fish \\
\hline
\end{tabular}

Western-style and franchise fast foods were considered as snack and recreational foods by most of the participants in the urban and rural areas in the three countries. Therefore, they were not consumed very often. Some participants in FGD reported that they sometimes visited franchise fast-food outlets or restaurants, rather than the many traditional food outlets in their city, because 'nowadays, many traditional foods are available and easy to find'. They claimed to still prefer traditional food because they cannot change their food preference.

In Indonesia, all participants agreed that there had been little or almost no difference in food tastes between the two generations interviewed. The Minangkabau traditional food continued to be the first choice of the participants in West Sumatra. The taste preference of the people in West Sumatra was a combination of the hot and spicy, tinged with the flavour of herbs and spices, and a little bit of salt. Western foods such as McDonald's were hardly known to the villagers. However, the older generation mentioned that more food was available now compared with 40-50 years ago. Restaurants and food outlets can now be found everywhere. Novelty foods have also been introduced, such as instant noodles, tofu and tempeh, which were commonly used in households.

Although traditional food patterns were still maintained by most participants in the present study, they did inject some changes in the recipes. Some female participants in the Philippines reported that they put in more oil and butter when they prepare some traditional recipes. Some participants admitted that they now consume more sugary foods and juices than before. Fruit juices are considered as snacks and are therefore given to children. In Indonesia, all participants agreed that there was no difference in the food preparations of the older and the younger generations. The younger generations continue to use the same ingredients and the same processes in food preparation as the older ones, they said. Any possible differences came in the form of the cooking utensils used, like electric appliances such as rice cookers and food blenders. Like gas stoves, they can be found in many households in the villages.

\section{Discussion}

\section{Nutrition transition}

Nutrition transition in the South-East Asian countries has gone a long way. There have been tremendous increases in the prevalence of obesity among adults and children, and in the risks attendant to obesity such as diabetes mellitus, CHD and stroke, even as problems of undernutrition such as underweight, severe malnutrition, anaemia and iodine deficiency remain undefeated.

The nutrition transition in the Philippines has been reflected in changes in the proportions of macronutrients and food intakes, and in dramatic shifts in the causes of death from infectious diseases to chronic non-communicable diseases. Deaths from infectious diseases have shown a progressive descent since the 1940s, while deaths from heart disease and cancer have increased progressively. In the early 1990s, diseases of the heart and the vascular system were reported to be the top two causes of death in 
the Philippines ${ }^{(9)}$. On the other hand, there have been steady decreases in the prevalence of undernutrition in children in the Philippines, from $34.55 \%$ in 1990 to $24 \cdot 6 \%$ in 2006 . However, obesity was also found to afflict $14 \cdot 0 \%$ of the children in Manila and $24.5 \%$ of the adults.

The performance of the Philippine economy has been remarkable over the past 26 years, inclusive of mid-1997 or during the economic crisis. Gross Domestic Product increased dramatically from Php600 million in 1980 to Php1200 million in 2006. Such high economic growth increased food availability and enhanced the purchasing power of the people, thereby accelerating the nutrition transition.

Since attaining independence in 1957, Malaysia has achieved marked socio-economic development including advances in the health-care delivery system. Vital data over the decades have shown much improvement in the health status of Malaysians, in general. Malaysia was seen to have better socio-economic and health status than several countries in the South-East Asian region in terms of life expectancy at birth $(74.5$ years for women and $70 \cdot 1$ years for men) and infant, toddler and maternal mortality rates (9, 10 and 39 per 100000 live births, respectively ${ }^{(10)}$. The nutritional status of Malaysians mirrors a society that is undergoing nutrition transition. Consequences of the dual burden of under- and overnutrition are evident in various age groups in rural and urban areas. On the one hand, protein-energy malnutrition persists as shown by the prevalences of underweight and stunted growth among children in rural areas, which ranged between 20 and $30 \%$, and 25 and $35 \%$, respectively, in $1997^{(11)}$. These decreased from $16 \cdot 0 \%$ to $13 \cdot 2 \%$, and from $19 \cdot 4 \%$ to $15 \cdot 8 \%$, as per the Third National Health and Morbidity Survey (NHMS III) in $2006^{(12)}$. In contrast, the prevalence of overweight children and adolescents in urban areas has been growing such that, from a range of $5 \cdot 4-6 \cdot 3 \%$ in 1996 , it rose to $18-19 \%$ ten years later ${ }^{(13,14)}$. The number of overweight adults has similarly risen. The Second National Health and Morbidity Survey of the Ministry of Health Malaysia reported that $26.5 \%$ of the adult population was overweight in 1997; the figure rose to $29 \cdot 1 \%$ in $2008^{(15)}$.

Trends in the patterns of household expenditure and food consumption confirm the picture on the nutrition transition in South-East Asia. In Malaysia, there has been a significant increase in per capita consumption of wheat, from $33 \mathrm{~kg}$ in 1990 to $58 \mathrm{~kg}$ in 2005. In contrast, rice consumption per capita declined by about $15 \%$ over the same period. Despite this development, rice remains the major staple and provides close to one-third of the daily energy intake, on average. Per capita consumption of starchy roots also declined markedly between 1990 and 2005 , with a significant decline in the consumption of cassava. Compared with other rapidly growing Asian countries, Malaysia's per capita consumption of livestock products is relatively high. For example, consumption of meat in Malaysia was about $48 \mathrm{~kg}$ per capita in 2005 . This compares with about $35 \mathrm{~kg}$ per capita in both Japan and the Republic of Korea, and $24 \mathrm{~kg}$ per capita in Thailand ${ }^{(16)}$.

There have been remarkable changes in the Indonesian economy as well: even though the average economic growth rate of $7 \cdot 8 \%$ per annum in the 1970 s decreased to $6.5 \%$ in the 1980 s, it increased to $7.2 \%$ per annum a decade later. Such high economic growth increased food availability and enhanced the purchasing power of the people, which, in turn, accelerated the nutrition transition. A shift from labour-intensive occupations in the rural primary product sectors of agriculture, forestry and fisheries to occupations in the service and manufacturing industries was in consonance with the marked increase in the Gross National Product of Indonesia. This transition was linked to a major reduction in energy expenditures at work. Life expectancy changed dramatically, from 42 to 67 years for men and from 47 to 69 years for women from 1967 to 2008, respectively. Indonesia, like many other developing countries, is experiencing a nutrition transition which is being reflected in the rapid changes in diet structure and causes of death.

In Indonesia, consistent with significant improvements in living standards, the proportion of household expenditure on food has fallen steadily since 1969-1970, with most of the decline accounted for by the cereal and tuberous food groups. Correspondingly, the proportion of household expenditure on non-food items has risen and there has been a sharp increase in housing and utilities expenditures. Expenditures for meats, eggs and milk have increased significantly, however.

Expenditures for prepared food have also increased, by $100 \%$ more than for any other food item over the period 1985 to 2007. This was due to more women entering the labour force. From only $32.60 \%$ in 1980 , women accounted for $39.60 \%$ of the labour force in 1985 and for $49.93 \%$ in 1997. This phenomenon might have resulted in women having less time available to prepare food at home ${ }^{(17,18)}$.

There have been remarkable changes in food intake during the years 1983 to 2004. Fish consumption remained similar, at $52 \mathrm{~g} / \mathrm{d}$ in 1983 and $54 \mathrm{~g} / \mathrm{d}$ in 2004 . The largest increases were found for soya and, to a lesser extent, for meat, eggs and dairy products. In 1983, consumption of soya was $10 \mathrm{~g} / \mathrm{d}$, but in 2004 the consumption had increased to $110 \mathrm{~g} / \mathrm{d}$. In contrast, rice and cereal consumption decreased significantly from $1007 \mathrm{~g} / \mathrm{d}$ in 1983 to $512 \mathrm{~g} / \mathrm{d}$ in 2004 . To demonstrate the trends in dietary nutrient intakes, results from two case studies made in West Sumatra are reported. There was a dramatic change in the proportional intakes of macronutrients (computed as percentage contribution to total energy intake) between 1983 and $2004^{(19)}$. Although the average total energy intake was not different, the ratio of energy from carbohydrates, protein and fat in 1983 was 82:8:10, indicating that the energy intake was mainly from carbohydrates, and that fat and protein did not contribute much. After 21 years, the 
ratio shifted to $54: 18: 28$, which shows that carbohydrates still contributed the greatest proportion of energy but to a much lesser extent. The ratio also showed an increase in fat and protein consumption. The increase in protein intake paralleled the substantial increase in meat and dairy products consumption. Fat-derived energy intake increased throughout the period, from $10 \%$ to $28 \%$. The change in the energy contributions of carbohydrates, protein and fat, percentage wise, may give a broad picture of the nutrition transition in Indonesia.

\section{Dietary habits and food culture}

The study showed that most of the participants still maintained their own food consumption patterns. However, the limited number of FGD in each country and small number of participants in the interviews may not represent the whole population in the three countries. The nutrition transition in the region could not be explained by the introduction of Western foods, because the practice of consuming Western foods among the study population was minimal. Although international food franchises can be easily found on every corner in big cities such as Manila and Kuala Lumpur, Western foods were considered as snack foods that were consumed for recreation and leisure.

The present study also showed that there has been only a slight change in food preferences among the participants. Most of the participants have not changed their dietary patterns. There was little or almost no change in food preferences between the younger and the older generations. A similar pattern of preserving traditional food patterns was found in Korea. Kim and Popkin and Lee et al. reported a recent boom in the demand for traditional restaurants in South Korea ${ }^{(20,21)}$. In Thailand, although there was an initial association between shopping at supermarkets and attributing bread with culinary value, both regular supermarket shoppers and fresh market shoppers were similarly likely to affirm the symbolic importance of rice ${ }^{(22)}$.

Popkin and co-workers revealed that the nutrition transition in many developing countries has been reflected in dramatic shifts in food consumption ${ }^{(4,23)}$. These diet shifts include large increases in energy density and in the proportion of the population consuming a high-fat diet and more animal products. People living in urban areas consume foods that are distinctly different from those of their rural counterparts.

One of the more profound effects of nutrition transition is the accelerated change in the structure of diets, which can only partially be explained by economic factors. The improvement of economic status in the three South-East Asian countries studied here has increased people's food purchasing power. But this does not necessarily mean that people have changed their food preferences.

The addition of more animal products, sugar and oil to the same traditional recipes was probably the major cause of the increasing obesity that resulted from nutrition transition in the region. The increased availability of palm oil in Malaysia and Indonesia, and of coconut oil in the Philippines, may also have had a role, as noticed by Drewnowski and Popkin ${ }^{(24)}$. In China, the consumption of food derived from fat and refined carbohydrates had grown as in many developing countries. Moreover, the cultural perceptions of diet quality, influenced by commercial advertisements, have led to the consumption of more products containing refined sugar ${ }^{(6)}$.

\section{Conclusions}

The results of the present study showed that Malaysians, Filipinos and Indonesians have retained many aspects of their traditional diets, although there was a significant difference in the food varieties of the urban $v$. the rural areas. The Western food franchises and culture have not yet overwhelmed the local food culture in this region. The rapid nutrition transition in this region may be due, instead, to the increasing availability of food and the increase in the food purchasing power of the people, rather than to a shift in food preference for modern Western foods.

\section{Acknowledgements}

Source of funding: The work was supported by The Japan Foundation through the Asia Public Intellectual Fellowship (batch VIII, 2008/2009). Conflicts of interest: There are no conflicts of interest. Authors' contributions: N.I.L. designed and conducted the study in the three countries, analysed the data and wrote the manuscript. K.G.L. helped to design the study in Malaysia and read the manuscript. I.A.-A. helped to design the study in the Philippines. Acknowledgements: The authors thank the people in Pincuran Panjang, Kubang, Nareh and Kalumbuk (Indonesia), Bandar Baru Bangi and Tanjong Karang (Malaysia), and Taguig and Calabanga (Philippines), without whose help the study would not have been completed.

\section{References}

1. Popkin BM (1998) The nutrition transition and its health implications in lower-income countries. Public Health Nutr 1, 5-21.

2. Romieu I, Hernandez-Avila M, Rivera JA et al. (1997) Dietary studies in countries experiencing a health transition: Mexico and Central America. Am J Clin Nutr 65, 4 Suppl., 1159S-1165S.

3. Vorster HH, Bourne LT, Venter CS et al. (1999) Contribution of nutrition to the health transition in developing countries: a framework for research and intervention. Nutr Rev $\mathbf{5 7}$, 341-349.

4. Popkin BM (2001) The nutrition transition and obesity in the developing world. J Nutr 131, issue 3, 871S-873S. 
5. Misra A, Singhal B, Sivakumar B et al. (2011) Nutrition transition in India: secular trends in dietary intake and their relationship to diet-related non-communicable diseases. J Diabetes 3, 278-292.

6. Monteiro CA, Conde WL \& Popkin BM (2004) The burden of disease from undernutrition and overnutrition in countries undergoing rapid nutrition transition: a view from Brazil. Am J Public Health 94, 433-434.

7. Kato I, Suketami T \& Tetsuo K (1987) Relationship between westernization of dietary habits and mortality from breast and ovarian cancers in Japan. Jpn J Cancer Res 78, 349-357.

8. Savige GS, Hsu-Hage B \& Wahlqvist ML (1997) Food variety as nutritional therapy. Curr Ther 3, 57-67.

9. Dayrit CS (2003) Coconut oil: atherogenic or not? (What therefore causes atherosclerosis?). Philipp J Cardiol 31, 97-104.

10. Lim TO, Ding LM, Zaki M et al. (2000) Distribution of body weight, height and body mass index in a national sample of Malaysian adults. Med J Malaysia 55, 108-128.

11. Khor GL (1997) Nutritional status of children in Malaysia: persistence of old problems. Malaysia J Child Health 9, 133-150.

12. Hussein Z (2008) Prevalence of Diabetes Mellitus In Malaysia in 2006 - Results of the 3rd National Health Measurement Study (NHMS III). Kuala Lumpur: Diabetes Study Group, Ministry of Health Malaysia.

13. Bong ASL \& Jaafar S (1996) Obesity among years 1 and 6 primary school children in Selangor Darul Ehsan. Malays J Nutr 2, 21-27.

14. Zalilah MS, Mirnalini K, Khor GL et al. (2006) Estimates and distribution of body mass index in a sample of Malaysian adolescents. Med J Malaysia 61, 48-58.
15. Department of Statistics, Malaysia (2008) The National Health Measurement Study (NHMS IV). Kuala Lumpur: Public Health Institute, Ministry of Health Malaysia.

16. Warr S, Rodriguez G \& Penm J (2008) Changing Food Consumption and Imports in Malaysia: Opportunities for Australian Agricultural Exports. Canberra: Australian Bureau of Agricultural and Resource Economics.

17. Central Bureau Statistics of West Sumatra (2008) National Socio-economic Survey (SUSENAS) of West Sumatra. Padang: Section Demographic and Household Statistics.

18. Soemantri S, Budiarso RL, Suhardi S et al. (1997) Household Health Survey. Jakarta: Ministry of Health.

19. Lipoeto NI, Wahlqvist ML, Wattanapenpaiboon $\mathrm{N}$ et al. (2004) Dietary intake and the risk of coronary heart disease among the coconut consuming in West Sumatra, Indonesia. Asia Pac J Clin Nutr 13, 20-26.

20. Kim S \& Popkin BM (2000) The nutrition transition in South Korea. Am J Clin Nutr 71, 44-53.

21. Lee MJ, Popkin BM \& Kim S (2002) The unique aspects of the nutrition transition in South Korea: the retention of healthful elements in their traditional diet. Public Health Nutr 5, 197-203.

22. Isaacs BA, Dixon J \& Banwell C (2010) Fresh market to supermarket: nutrition transition insights from Chiang Mai, Thailand. Public Health Nutr 13, 893-897.

23. Popkin BM, Adair LS \& Ng SW (2012) Global nutrition transition and the pandemic of obesity in developing countries. Nutr Rev 70, 3-21.

24. Drewnowski A \& Popkin BM (1997) The nutrition transition: new trends in the global diet. Nutr Rev $\mathbf{5 5}$, $31-43$. 